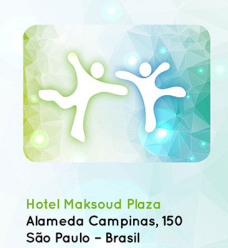

\title{
VALIDAÇÃO PARA O PORTUGUÊS (CULTURA BRASILEIRA) DO "TEST FOR RESPIRATORY AND ASTHMA CONTROL IN KIDS" (TRACK) \\ Pôster \\ Autores deste trabalho:
}

Gustavo Falbo Wandalsen: UNIFESP

Herberto J. Chong-Neto: UFPR

Lillian Moraes: UFMT

Neusa F. Wandalsen: Faculdade de Medicina do ABC

Décio Medeiros: UFPE

Marilyn Urritia-Pereira: UNIPAMPA

Dirceu Solé: UNIFESP

Grupo TRACK Brasil: UNIFESP

Área do Trabalho: Pediatria

Data da submissão: 05/08/2018 às 11:37

\section{Justificativa}

O questionário TRACK (Test for Respiratory and Asthma Control in Kids) é um instrumento desenvolvido e validado em língua inglesa para avaliar o controle dos sintomas respiratórios de crianças menores de cinco anos.

\section{Objetivo(s)}

Validar a versão traduzida para o português (cultura Brasileira) do questionário TRACK.

\section{Método(s)}

A validação foi feita em estudo observacional, prospectivo e multicêntrico (seis centros) com crianças com sintomas respiratórios recorrentes. O estudo foi aprovado pelo comitê de Ética da Instituição (CAAE: 57313416.1.1001.5505). As crianças foram classificadas de acordo com os sintomas, com os critérios da GINA e com a opinião médica. Pais e médicos também quantificaram os sintomas respiratórios do último mês (EVA).

\section{Resultado(s)}

No total foram obtidos dados de 299 crianças na avaliação inicial e de 195 na visita de seguimento. A mediana dos escores do TRACK foi de 65 pontos ( 0 a 100 pontos) e o coeficiente de Cronbach foi de 0,70. Os escores do TRACK se correlacionaram significantemente com a opinião médica e da família sobre os sintomas respiratórios ( $r$ : 0,74 e $r$ : 0,61). Os escores do TRACK foram significantemente menores nas crianças que utilizaram corticosteroide sistêmico (mediana [IIQ]: 45 [30 - 65] vs 75 [55 - 80]; $p<0,001$ ) e necessitaram atendimento de urgência no último mês (45 [35 60] vs 70 [55 - 80]; $p<0,001)$. Os escores do TRACK foram significantemente diferentes quando as crianças foram separadas pela opinião médica, pela GINA e pelos sintomas. Oitenta pontos foi o ponto de corte do questionário com maior área sobre a curva $\operatorname{ROC}(0,800)$ para separar crianças com e sem dificuldades no controle 
dos sintomas respiratórios.

\section{Conclusão (ões)}

A versão traduzida para o português do questionário TRACK apresentou confiabilidade satisfatória (consistência interna), adequada validação por critério (comparação com os critérios da GINA) e validação construtiva (comparação com os sintomas respiratórios e a opinião médica), demonstrando ser um instrumento útil para avaliar e discriminar crianças com sintomas respiratórios. 